\title{
Students' school climate perceptions: do engagement and burnout matter?
}

\author{
Luisa Molinari $^{1}$ D $\cdot$ Valentina Grazia $^{1}$
}

Received: 29 October 2020 / Accepted: 10 August 2021 / Published online: 21 August 2021

(c) The Author(s) 2021

\begin{abstract}
This study, conducted with a person-oriented approach, aimed to assess whether students who are positively engaged in school activities and daily practices perceive their school climate differently from students who feel distant and less engaged in school. To achieve this aim, by means of a Latent Profile Analysis with the 3-step approach, we first identified student profiles on the basis of their levels of school engagement and burnout, and then verified whether the school climate perceptions differed for the various profiles. The study involved 1065 Italian middle-school students $\left(49 \%\right.$ females, $\left.M_{\text {age }}=11.77\right)$. School climate perceptions were assessed with the Multidimensional School Climate Questionnaire. Multidimensional measures were used for student engagement and school burnout. Four student profiles, labelled Cynically disengaged (5.9\%), Moderately disengaged (21.6\%), Peacefully engaged (46.1\%) and Tenseley engaged (26.4\%), were identified. The first two profiles involved low levels of engagement and high levels of cynical burnout, with the former showing more extreme scores. The other two profiles depicted engaged students, with the latter also revealing feelings of pressure and disillusion. The four profiles differed in their school climate perceptions, with the Peacefully engaged students reporting the highest scores and the Cynically disengaged students embodying the most critical perceptions. The study's educational implications are discussed.
\end{abstract}

Keywords Latent profile analysis · Middle-school students · Person-oriented approach · School burnout $\cdot$ School climate $\cdot$ Student engagement

\section{Introduction}

School climate is a multidimensional construct that captures the complex and multifaceted nature of the learning environment (for a comprehensive review, see Wang \& Degol, 2016). It has received growing interest from scholars in the last decades, mostly because of the evidence that school climate research can provide important information for the implementation of interventions (Voight \& Nation, 2016) leading to improvements in the learning

Luisa Molinari

luisa.molinari@unipr.it

1 Department of Humanities, Social Sciences and Cultural Industries, University of Parma, Borgo Carissimi 10, 40125 Parma, Italy 
environment (Cohen et al., 2009; Thapa et al., 2013). The results of school climate research consistently show that perceptions of a good school climate are positively associated with learning and academic achievement (Berkowitz et al., 2017) and can prevent negative outcomes, such as problem behaviours or violence in school (Reaves et al., 2018; Steffgen et al., 2013). Less is known, however, about the associations between school climate and the way students feel and act in school. To bridge this gap, the present study addressed the following question: Do students who are positively engaged in school activities and daily practices perceive their school climate differently from students who feel distant and less engaged in school? To answer this question, we adopted a person-oriented approach for identifying student profiles on the basis of their levels of school involvement, and then explored perceptions of their learning environment, by searching for the profiles' associations with school climate dimensions.

\section{School climate}

Defined as "the quality and character of school life" (Cohen et al., 2009, p. 182), the construct of school climate includes both the intangible school atmosphere (e.g. relational and belongingness feelings) and the more-concrete classroom life (daily teacher-student interactions and didactic practices) (Reyes et al., 2012). Given these broad features, research on school climate calls for a systemic theoretical approach (Rudasill et al., 2018), which offers a wide perspective for understanding and interpreting the interdependent transactions and relationships between and among individuals and groups that occur in the proximal classroom system as well as in the more general school system.

Research on school climate has mostly been carried out with a variable-centred approach, allowing scholars to investigate general trends and associations between variables. Results consistently showed that better perceptions of school climate are associated with higher academic achievement (Kutsyuruba et al., 2015; Maxwell et al., 2017; Reynolds et al., 2017) and lower levels of violence and problem behaviour (Johnson, 2009; Reaves et al., 2018; Steffgen et al., 2013). Moreover, school climate was found to relate to students' mental health (Aldridge \& McChenney, 2018; Jamal et al., 2013) and teachers' psychological wellbeing (Gray et al., 2017).

In this study, we provide a contribution by adopting a person-oriented approach to exploring whether groups of students with positive or negative experiences of school involvement in terms of engagement and burnout differ in their school climate perceptions, keeping distinct the two aspects of classroom practices and school atmosphere.

\section{School experiences of engagement and burnout}

Student engagement in school activities is generally described as a positive, flourishing experience (Fredricks et al., 2004; Reschly et al., 2008). The construct is multidimensional, comprising four aspects. Emotional engagement is defined as the student's reaction to teachers, classmates and school-related experiences. Behavioural engagement refers to the student's involvement in school activities. Cognitive engagement indicates the processes and strategies that students use to elaborate learning contents. The fourth component, which was added more recently (Mameli \& Passini, 2017), is called agentic engagement and involves students' active role and transformative contributions provided to the ongoing flow of the education that they receive. 
Overall, the concept of student engagement is considered crucial for ameliorating the educational paths of young generations (Appleton et al., 2008; Jelas et al., 2016; Lawson \& Lawson, 2013). Moreover, it has been claimed that student engagement is associated with the feeling that learning in school is important for achieving personal goals. However, this is only one side of the coin. Fewer studies have actually shown that, in some cases, the experience of energy, dedication and absorption entailed by student engagement goes together with negative feelings, such as those of exhaustion or inadequacy, which are typical symptoms of student burnout (Salmela-Aro et al., 2009). In studies conducted with high-school students, when Salmela-Aro and collaborators (Salmela-Aro \& Read, 2017; Salmela-Aro et al., 2016) combined emotional engagement and burnout with a person-oriented approach, various students' profiles with different levels of the two variables emerged. As predicted, there were students who felt emotionally engaged in school activities and perceived no burnout, whereas other students experienced high levels of burnout and no engagement. However, the central and most-interesting finding of the study involved a group of students, labelled 'engaged-exhausted', who experienced what the authors called the "dark side of student engagement" (Salmela-Aro et al., 2016, p. 68) which was characterised simultaneously by high levels of emotional engagement and exhaustion. This result, which contrasts with the common definition of engagement as a definitely-positive experience, has many clinical implications because engaged-exhausted students are at risk of developing symptoms of depression in the long run (Tuominen-Soini \& Salmela-Aro, 2014).

Drawing on the interesting insights provided by this line of research, we adopted a person-oriented approach for identifying, in a population of middle-school students, profiles resulting from the combination of engagement and burnout, and then we explored perceptions of their learning environment by searching for the profiles' associations with school climate dimensions.

\section{School climate associations with student engagement and burnout}

There is limited evidence about the associations between students' engagement and school climate perceptions. However, the few existing studies in the field have provided some interesting results. For example, Fatou and Kubiszewski (2018) found that several dimensions of school climate were positively associated with student engagement, especially as far as its affective component was concerned, and Wang \& Eccles, 2012) found a positive relation between better school structure and higher behavioural and emotional engagement. Other studies supported the positive role of school climate in the promotion of student engagement (Yang et al., 2020), while also underlining cultural differences. For example, the results of a cross-cultural study comparing American and Chinese students (Bear et al., 2018) showed that the relation between school climate and engagement was significant only for the American students. These results indicate that the association between school climate and student engagement is a promising field of study, but more research is needed. However, associations between school climate and student burnout, to the best knowledge, has been investigated very seldom so far. Among the few studies in the field, Shih (2015) found a negative association between perceived classroom structure and burnout in Taiwanese students. Research in this area has important educational implications, because knowing whether the way in which young students feel and act in school relates to school climate can inform interventions for improving the learning environment. 


\section{Study rationale and aims}

Following Salmela-Aro and collaborators' suggestion to further exploit a person-oriented approach, we built on the literature in the current study in three ways. First, while previous person-oriented studies on engagement and burnout were carried out in high schools (Salmela-Aro et al., 2016) or universities (Tuominen-Soini \& Salmela-Aro, 2014) students, we used the same approach to explore unique patterns of engagement and burnout in a population of early adolescents. This research is needed because it offers the possibility to identify students at risk of disengaging from school. Moreover, and contrary to previous person-oriented work that generally has considered only one dimension of engagement (mostly affective or emotional), this study accounted for the four-component model of engagement. This allowed us to achieve a more-nuanced view of how early adolescents perceive their involvement in school. Lastly, we analysed whether the emerging profiles of students' involvement in school were accompanied by different perceptions of many school climate dimensions, an issue that never has been addressed before and that is important for finding ways to improve the learning environment.

There were two were research aims. First, we identified student profiles based on their levels of engagement and burnout. Drawing on the results of previous studies (SalmelaAro et al., 2016), we expected to find a group of students who were highly engaged and showed low levels of burnout, a group of students with high levels of burnout and low engagement, and a group of students with mixed levels of engagement and burnout. At this stage, we also controlled for the role of gender and school grade. The second aim was to explore whether the students belonging to the identified profiles showed different school climate perceptions, assessed in the multidimensional features of classroom practices and school atmosphere.

\section{Methods}

\section{Participants}

This study involved 1065 participants (49\% females, 93\% born in Italy) from four mixed-gender middle schools in Northern Italy. Participants were aged from 10 to 13 years $\left(\mathrm{M}_{\mathrm{age}}=11.77, \mathrm{SD}_{\mathrm{age}}=0.72\right)$ and were all enrolled in the 6th or 7 th grade. Their socio-economic status (SES) was not assessed directly for this study, but the official website of the Italian Ministry of University and Research (MIUR) reveals that participating schools are attended by students from medium socio-economic contexts, with a percentage (between 10 and $20 \%$ ) of students being mostly second-generation immigrants coming chiefly from Northern Africa and Eastern Europe.

\section{Procedure}

The research was conducted in agreement with the Italian National Psychological Association's ethical norms. After obtaining parental consent (only 1\% of parents refused), the researcher administered the questionnaire during class hours, using computers and online software that allows the randomization of the item order for each participant. All 
students received the same instructions and, after being briefed about the research aims, were asked for voluntary participation and assured of anonymity.

\section{Measures}

For each of the following scales, participants answered on a 6-point Likert scale ranging from Completely Disagree to Completely Agree, with higher scores indicating higher engagement, higher burnout and better school-climate perceptions. Cronbach's alpha reliability for each measure and dimension, along with descriptive statistics and intercorrelations, are reported in Table 1.

\section{Student engagement}

We used an instrument already validated with an Italian population (Mameli \& Passini, 2017) and comprising four dimensions of engagement: Emotional (sample item: "I have fun learning something new"), Behavioural (sample item: "In class I work as hard as I can"), Cognitive (sample item: "When I study I try to find links between topics") and Agentic (item sample: "In class I express my preferences and opinions"). With agreement of the authors, we used an abbreviated version with 16 that had the highest factor loadings in the validation. To test the goodness-of-fit of this abbreviated version of the questionnaire with our population, we conducted a preliminary confirmatory factor analysis (CFA). The expected four-factor model had good indices of fit: RMSEA $=0.047$ [0.042-0.053], $\mathrm{CFI}=0.943, \mathrm{SRMR}=0.054$.

\section{School burnout}

We used the 9-item Italian adaptation (Fiorilli et al., 2014) of the School Burnout Inventory (Salmela-Aro et al., 2009) comprising three dimensions: Exhaustion (sample item: "I feel overwhelmed by schoolwork"), Cynicism (sample item: "I often wonder whether school has any meaning") and Inadequacy (item sample: "In the past I had better expectations toward school than I have now"). Because students involved in this study were younger than those involved in the original Italian adaptation of the measure, we first explored the psychometric properties of the inventory and then conducted a CFA with our population. These analyses showed that the Inadequacy dimension was not adequate (Cronbach's alpha $=0.58$ ), perhaps because it was misunderstood by our population of early adolescent students. Thus, we excluded this dimension, with its two indicators, and tested the goodness-of-fit of a two-factor (Exhaustion and Cynicism) scale with a CFA, which yielded good fit indices: RMSEA $=0.047$ [0.032-0.063], $\mathrm{CFI}=0.980, \mathrm{SRMR}=0.028$.

\section{School climate}

Among the many measures that were developed for studying school climate (for methodological reviews, see Grazia \& Molinari, 2020a; Ramelow et al., 2015), the 49-item student version of the Multidimensional School Climate Questionnaire (MSCQ) was chosen for this study. The MSCQ, an instrument validated for the Italian school contexts in two studies involving a total population of 1645 students aged from 10 to 16 years (Grazia \& Molinari, 2020b), is a multi-informant questionnaire grounded in a systemic approach (Janosz et al., 1998) and containing two broad sections, one on Classroom 


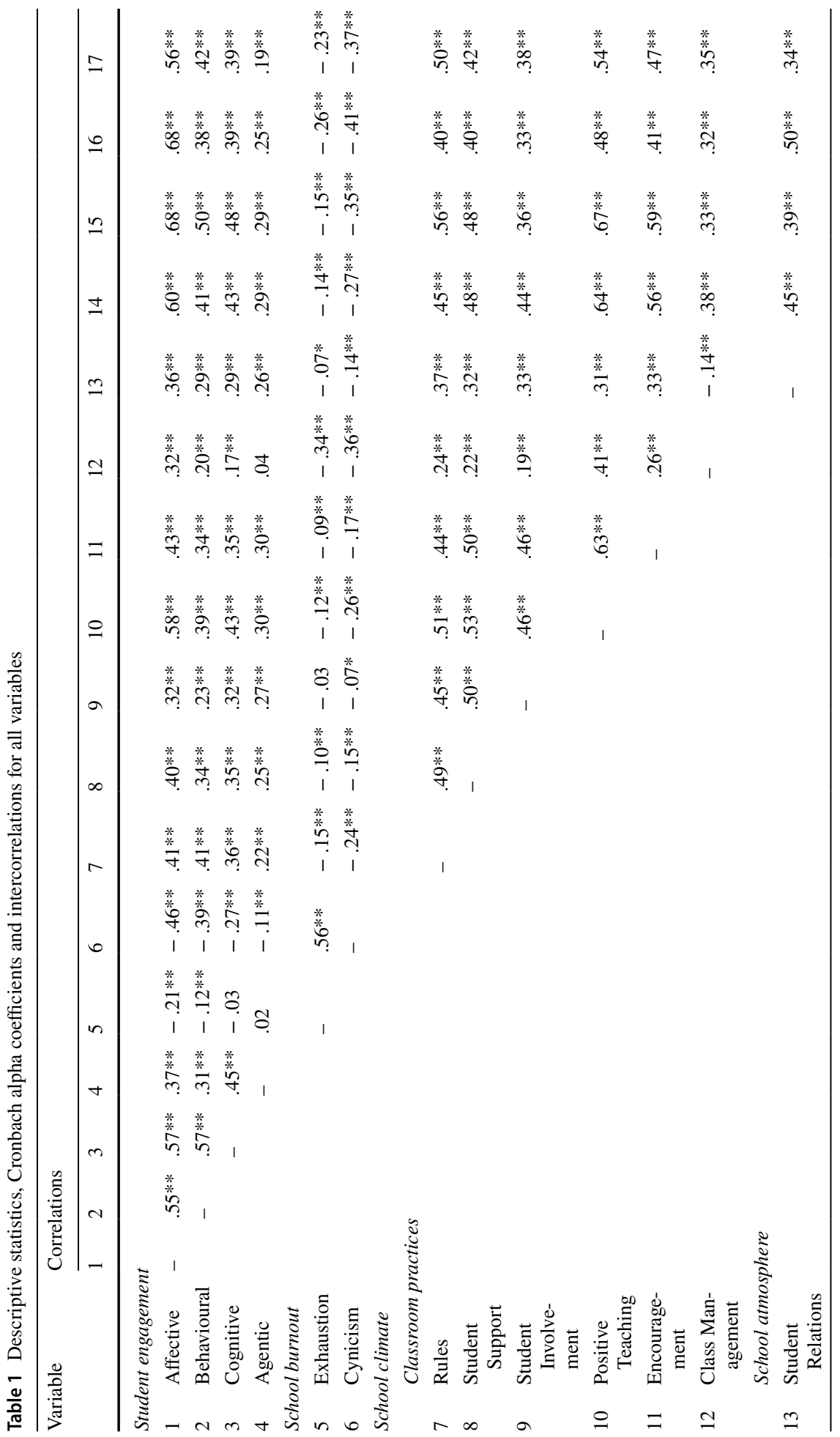




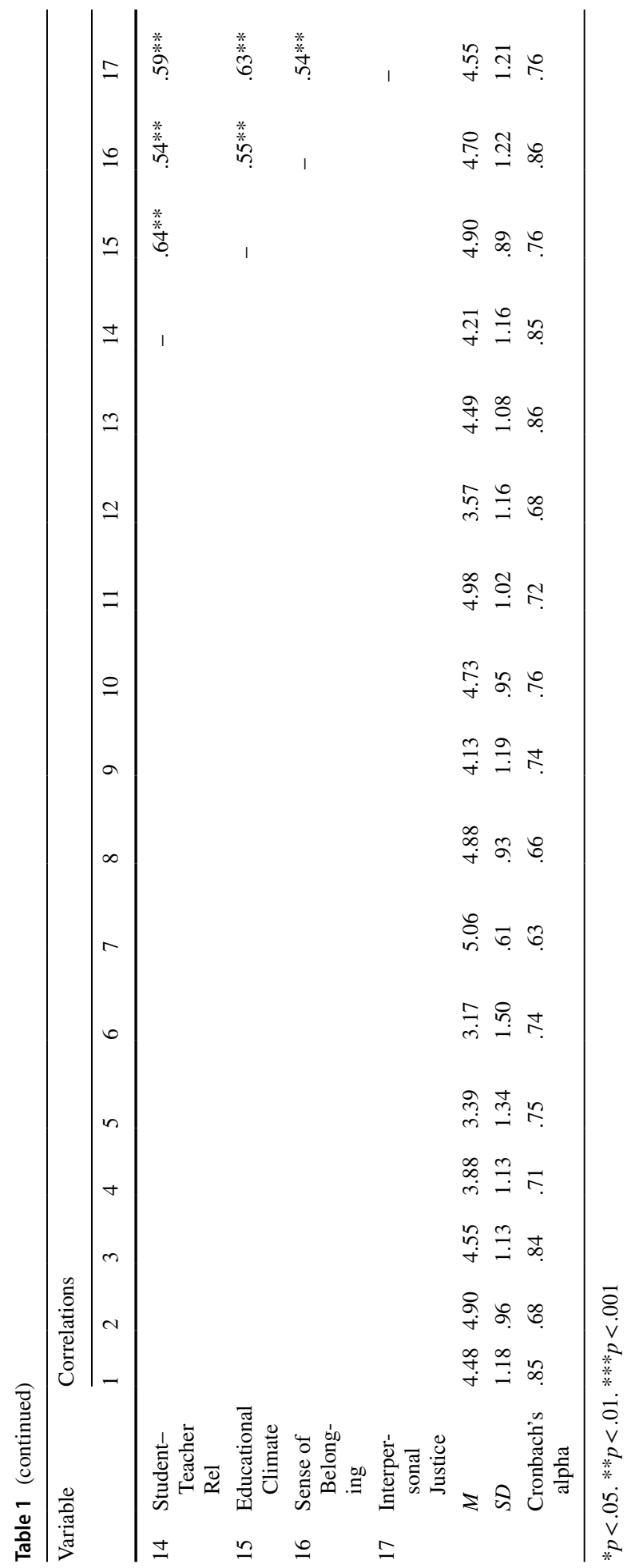


Practices and one on School Atmosphere. The Classroom Practices section comprises six dimensions, namely, Rules (sample item: "The rules are clear and easy to understand"), Student support (sample item: "If students have academic problems, they can easily get help from teachers"), Student involvement (sample item: "Students are asked for their opinion on the school functioning"), Positive teaching (sample item: "Teachers explain why what we study is important"), Encouragement (sample item: "Teachers tell us that we can do it"), and Class management (sample item: "Teachers lose their temper easily"; item to be reversed). The School Atmosphere section comprises five dimensions: Student relations (sample item: "Students treat one another with respect"), Student-teacher relations (sample item: "In general, students and teachers get along with each other"), Educational climate (sample item: "You can feel that studying is important"), Sense of belonging (sample item: "I am proud to be a student of this school"), and Interpersonal justice (sample item: "Students are treated with justice").

\section{Data analysis}

To achieve our aims, we conducted a Latent Profile Analysis with the 3-step approach (Asparouhov \& Muthen, 2014) to allow us to identify student profiles based on engagement and burnout, and then we analysed their associations with school climate dimensions, while controlling for measurement errors in the identification of latent classes.

For our first aim, we used the four dimensions of student engagement and the two dimensions of school burnout to test models with 2-5 latent classes. Models were then compared through several fit indices: the Bayesian Information Criterion (BIC), the Vuong-Lo-Mendell-Rubin Likelihood Ratio Test (VLMR-LRT), the Bootstrapped Likelihood Ratio Test (BLRT), and the entropy value (Nylund et al., 2007). In the comparison of indices, lower BIC values and entropy values closer to 1 are preferred because they indicate better fit and clearer distinction of classes. Moreover, both likelihood ratio tests (VLM-LRT and BLRT) should be significant, indicating that, in the comparison of nested models, adding one class improves the fit. Beside fit indices we also considered interpretability and parsimony when selecting the best-fitting model. We also controlled for the role of gender and school grade in predicting the likelihood of profile membership by conducting a multinomial logistic regression. For our second aim, in line with the 3-step approach, we conducted $t$-tests to compare profiles of the mean perceptions of all school climate dimensions.

Table 2 Fit indices for the 2-5 classes models in the latent profile analysis

\begin{tabular}{llllll}
\hline $\begin{array}{l}\text { Number of } \\
\text { classes }\end{array}$ & Loglikelihood & VLMR- LRT & BLRT & BIC & Entropy \\
\hline 2 & -9542.024 & $p=.000$ & $p=.000$ & $19,216.492$ & .863 \\
3 & -9305.491 & $p=.000$ & $p=.000$ & $18,792.221$ & .793 \\
4 & -9205.424 & $p=.042$ & $p=.000$ & $18,640.883$ & .787 \\
5 & -9126.079 & $p=.057$ & $p=.000$ & $18,530.988$ & .762 \\
\hline
\end{tabular}




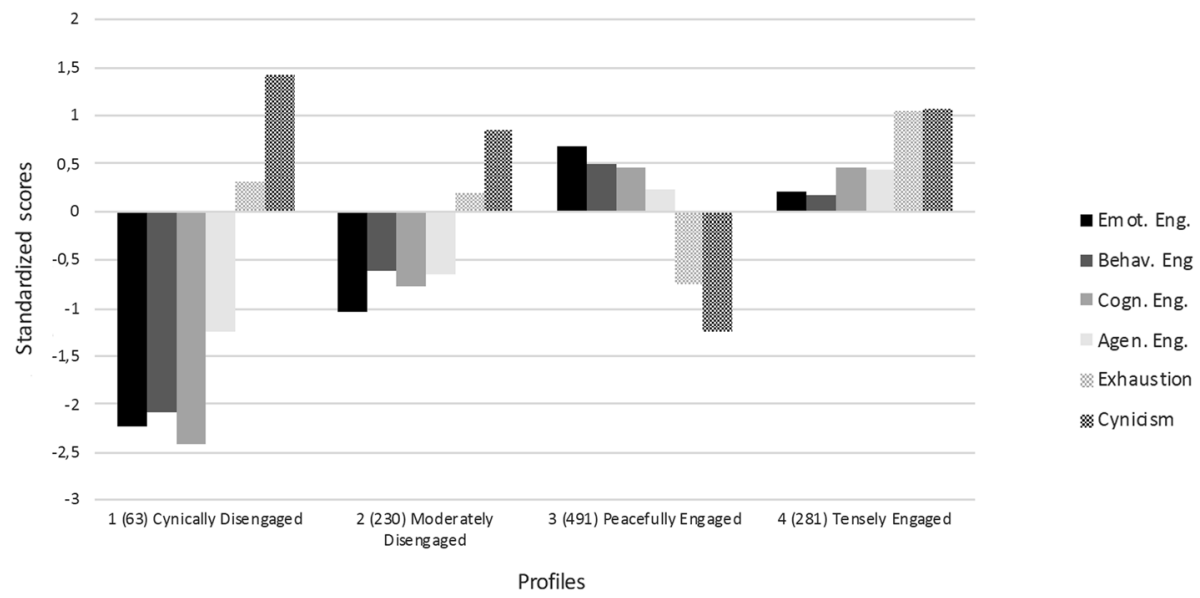

Fig. 1 Student profiles

Fig. 2 Distribution of students among the four profiles

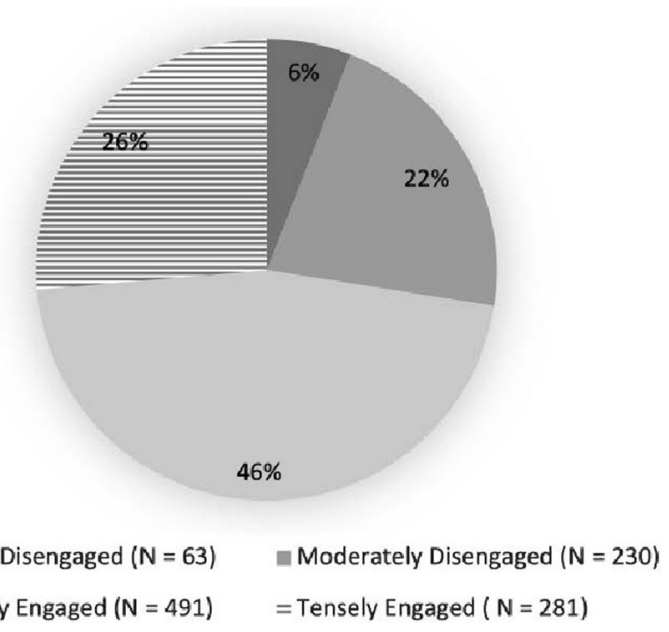

\section{Results}

\section{Student profiles}

The fit indices for 2-5 class Latent Profile Models are reported in Table 2. BIC values and BLRT did not distinguish among these models, suggesting that a larger number of classes might be best fitting. However, interpretability and parsimony of the model are also important and a number of classes higher than 5 would have been difficult to interpret. Thus, we considered the other likelihood ratio test, the VLM-LRT, which suggested that it was not necessary to have more than 4 classes. The best loglikelihood value for the 4 -classes model was replicated in more than one final stage solution, supporting it as a good solution. Consistently, the entropy value, decreasing with the addition of more classes, supported the 
choice of this model. Overall, the fit indices indicated that a 4-classes solution was the best-fitting model.

The four resulting profiles are represented in Fig. 1, where 0 corresponds to the mean score, and the distribution of students among profiles is represented in Fig. 2. The first profile (including 6\% of our population), which we called Cynically disengaged, included students reporting the lowest levels of all dimensions of engagement, alongside a score in exhaustion close to the average and a very high score in cynicism. A similar tendency, with weaker scores, characterised the second profile, which comprised a higher number of students (22\%) and that we called Moderately disengaged. Students reported low levels in all engagement dimensions and a rather high level of cynicism. The Peacefully engaged profile included a larger number of students (46\%) who reported the highest scores in emotional and behavioural engagement, and the lowest scores in both burnout dimensions that were well below the mean. The fourth profile, labelled Tenseley engaged, comprised the remaining students $26 \%$ of students, who reported scores close to the average in the emotional and behavioural dimensions of engagement, scores above the mean in cognitive engagement, the highest score (compared with the other profiles) in agentic engagement, and high scores in both dimensions of burnout.

When checking for the role of gender, we found that female students were less likely to belong to the Cynically disengaged profile as compared to the Moderately disengaged and to the Peacefully engaged profiles (respectively, $\mathrm{B}(\mathrm{SE})=1.00(0.37), p=0.007$ and $\mathrm{B}(\mathrm{SE})=1.53(0.34), p=0.000)$, and more likely to belong to the Peacefully engaged profile than to the Moderately disengaged $(\mathrm{B}(\mathrm{SE})=0.53(0.20), p=0.007)$ and to the Tensely engaged profiles $(\mathrm{B}(\mathrm{SE})=0.98(0.20) p=0.000)$. There was no significant gender difference between Cynically disengaged and Tensely engaged profiles.

School grade was significant in the comparison of the Cynically disengaged profile with the Peacefully engaged and Tensely engaged profiles: in both cases, older students $\left(7^{\text {th }}\right.$ grade) were more likely to belong to the first profile (respectively B $(\mathrm{SE})=0.96(0.30)$, $p=0.002$ and $\mathrm{B}(\mathrm{SE})=0.62(0.31), p=0.046)$. Lastly, in the comparison between the Moderately disengaged and Peacefully engaged profiles, older students were more likely to belong to the former $(\mathrm{B}(\mathrm{SE})=0.74(0.20), p=0.000)$.

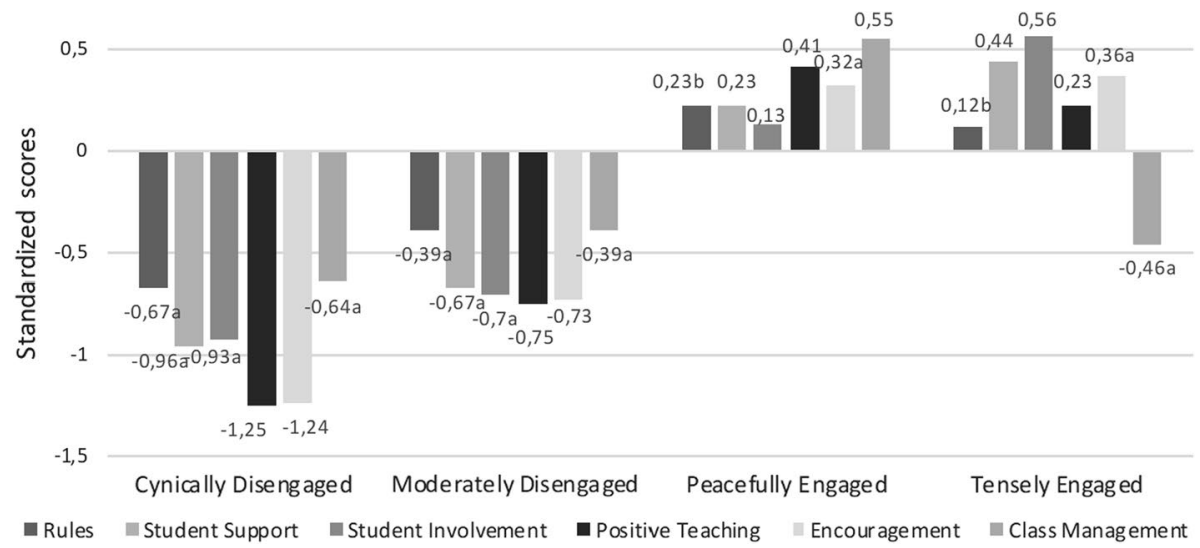

Fig. 3 Associations between profiles and perceptions of classroom practices. Note. The scores on the same dimension of Classroom Practices across profiles were all statistically different at $p<.05$ except the ones indicated with the same subscript for each dimension 


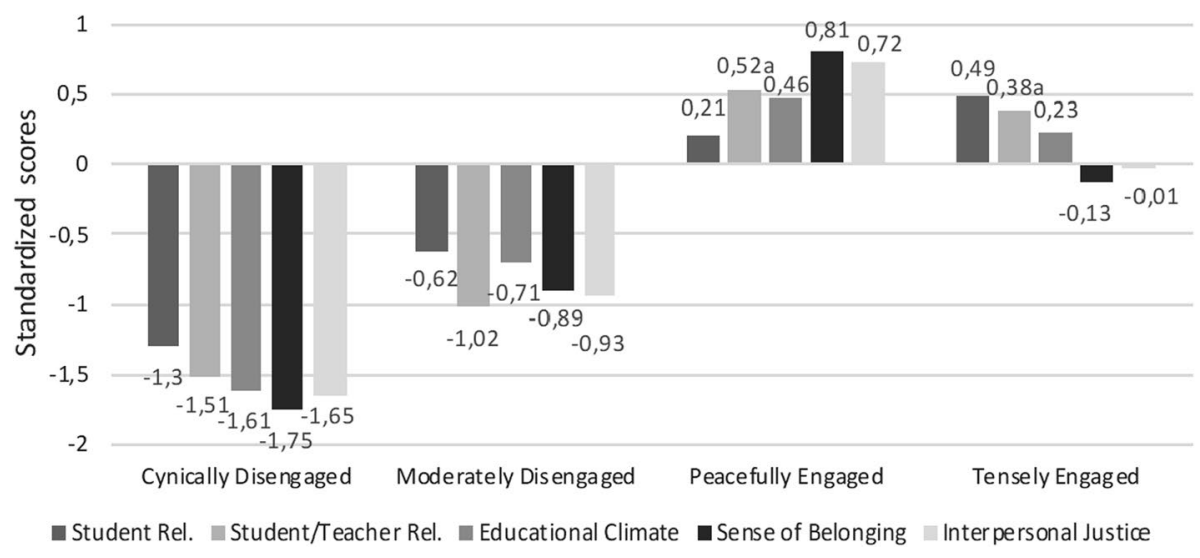

Fig. 4 Associations between profiles and perceptions of school atmosphere. Note. The scores on the same dimension of School atmosphere across profiles were all statistically different at $p<.05$ except the ones indicated with the same subscript for each dimension

\section{Associations with school climate perceptions}

Paired $t$-tests (Figs. 3 and 4) revealed that students in the different profiles reported significant differences in most dimensions of school climate. Starting with Classroom Practices dimensions (Fig. 3), the two disengaged profiles (Cynically and Moderately) involved scores well below the mean for all dimensions, and significantly lower than for the two engaged profiles, with the exception of the perception of Class management which was on level with the Tensely engaged profile. In the comparison between the two disengaged profiles, the Cynically disengaged students reported significantly-lower scores in Positive teaching and Encouragement. As far as the two engaged profiles were concerned, the overall picture was more positive with Tenseley engaged students reporting higher scores for Student support and Student involvement, lower scores for Positive teaching and muchlower scores for Class management.

With regard to the School Atmosphere dimensions (Fig. 4), the four groups reported significant differences for most dimensions, with the Cynically disengaged profile scoring the lowest, followed by the Moderately disengaged. The Peacefully and Tensely engaged profiles scored higher than the disengaged ones, with few differences between them. Notably, Tensely engaged students reported higher scores for Student relations, lower scores for educational climate and much lower scores for Sense of belonging and Interpersonal justice.

\section{Discussion}

The aim of this study was to employ a multidimensional perspective in analysing the relationship between engagement and burnout, and perceptions of the learning environment in terms of school climate. To achieve this aim, we first replicated previous research (SalmelaAro et al., 2016; Tuominen-Soini \& Salmela-Aro, 2014) based on a person-oriented approach for identifying subgroups of individuals with different profiles of engagement 
and burnout, by also adding the use of a multidimensional view of engagement and recruiting a younger student population. Secondly, we introduced a novel approach in the field by comparing various profiles in terms of classroom practices and school atmosphere dimensions, thus enriching our understanding of the learning environment. Key findings and educational implications are discussed in the following sections.

\section{Student profiles: pictures of early adolescent students}

Overall, the results from the Latent Profile Analysis supported our general expectations. In line with previous studies conducted with high-school students (Salmela-Aro \& Read, 2017; Salmela-Aro et al., 2016), similar patterns of engagement and burnout also pertained with younger students. This is an important result because it pinpoints the possibility of identifying students with severe levels of school malaise and develop interventions for promoting adaptive trajectories and preventing further risks.

As in previous studies, our use of a multidimensional measure of engagement offered further insights into the different profiles. In contrast to our predictions, we found two groups of students reporting low levels of engagement and high levels of burnout. This critical picture, which in total pertains to more than one student out of four, was more extreme for the Cynically disengaged profile and less extreme for the Moderately disengaged students, whose pattern was similar to the 'inefficacious' one found by Salmela-Aro et al., 2016). In line with a previous study conducted with older participants (Tuominen-Soini \& Salmela-Aro, 2014), students belonging to these two profiles reported feelings of burnout that strongly pointed toward a cynical attitude in school, while the perception of exhaustion attributable to study demands was much less intense. It is not surprising that cynicism is negatively correlated with engagement, because this burnout dimension is defined in terms of a distal attitude toward work and a loss of interest in activities that are considered as not meaningful (Salmela-Aro et al., 2009). However, by relying on a multidimensional measure of engagement, we were able to attach a more-nuanced picture of these students.

Differently from what described by Tuominen-Soini and Salmela-Aro (2014), the profile with the highest level of cynicism was also characterised by the lowest levels of engagement, especially as far as the emotional, behavioural and cognitive dimensions were concerned. This picture makes the Cynically disengaged students the most at risk for school problems, grade retention and dropout, which is consistent with findings from variable-oriented studies (Archambault et al., 2009; Bear et al., 2019). In addition, the relatively-small number of students clustered in this profile reported less-negative levels of agentic engagement, a dimension that is seldom considered in the studies of engagement (Mameli et al., 2018). This is an important and novel result that helps to better understand the characteristics of these students who, despite their general disengagement, perform some actions aimed at transforming a learning environment perceived as not meaningful (Matos et al., 2018).

This finding brings new insights to the recent debate about agency (Mameli et al., 2020), which is considered as taking a twofold meaning in the course of classroom dynamics. One form of agency basically conveys alignment with the teacher's directions, while another expresses resistance and challenge the teacher's power, especially in situations perceived to be unsatisfactory (Grazia et al., 2020). Having found that agentic engagement was higher, as compared with the other dimensions of engagement, in the cluster of Cynically disengaged students, we suggest that early adolescents make the effort to raise their voice in critical situations, presumably to produce intentional and strategic changes in their learning 
environment (Matos et al., 2018; Reeve \& Shin, 2020). This result opens reflections about the importance for teachers to care for these students, to listen and try to catch up with them in order to avoid their complete separation from school.

In contrast, a very encouraging picture emerged from the Peacefully engaged profile, which describes the most-adaptive pattern of engagement and burnout. These students, who comprised almost half of our total population, did not report burnout symptoms, thus declaring that they feel energy for their schoolwork and that going to school makes sense to them. They also perceived high levels of involvement in their school tasks, especially as far as the emotional component is concerned. The identification of an engaged and well-adapted profile is consistent with previous findings (Tuominen-Soini \& Salmela-Aro, 2014), even if it was not so numerically substantial in other studies (Salmela-Aro et al., 2016). In addition, inspection of the various dimensions of engagement shows that, contrary to what was found for the Cynically disengaged profile, the lowest score in engagement reported by these students concerned the dimension of agency. We can conclude that the Peacefully engaged profile comprises the 'good students', who are involved in school, feel happy about what they do and learn, and show a weak attitude to actions aimed at changing their environment.

The last profile confirms that, as expected, not all engaged students share an 'idyllic' vision of the school environment. Indeed, the Tensely engaged profile included students who are relatively involved in school but simultaneously experience high levels of burnout. In contrast to the disengaged students whose burnout was almost completely of a cynical type, the Tensely engaged students reported high levels of both cynicism and exhaustion. They thus can be described as highly-stressed and disillusioned students, who are engaged especially in the cognitive and agentic dimensions. These students in our sample embodied the dark side of student engagement already described by Salmela-Aro et al. (2016), because they seem to struggle and make an effort to participate and be involved by means of cognitive strategies in their learning and agentic behaviours in classroom interactions, but at the cost of a high level of pressure and disenchantment with school. The demandsresources model (Salmela-Aro \& Upadaya, 2014) provides an interpretative framework for this profile, which combines the positive process of engagement resources with the negative process of strain and fatigue demands.

The results of the control variables completed the profiles' picture. The findings concerning gender were consistent with the literature, showing that girls overall tend to follow more adaptive trajectories of engagement (Janosz et al., 2008). With regard to the role of school grade in predicting profile membership, older students were found to be more likely to belong to the less-adaptive profiles. While acknowledging that our data were crosssectional and therefore cannot inform on change over time, these findings, along with the higher number of students clustered in the most-adaptive profile in our study relative to studies with older students, suggest that there could be a tendency toward an increase with age in detachment and disillusion that needs to be confirmed in future longitudinal studies. If this tendency is confirmed, it would add novel elements to previous research showing a consistent decline in student engagement for older students (Lemos et al., 2020; Skinner et al., 2008).

\section{Associations of student profiles with school climate perceptions}

Opening a new line of inquiry with respect to previous person-oriented studies, we explored in the second aim of the present study associations between students' patterns of 
engagement and burnout and their perceptions of school climate. With regard to everyday Classroom Practices, our results are overall consistent with variable-oriented studies showing that various practices in the learning environment are associated to student engagement (Fredericks et al., 2004; Shih, 2015; Wang \& Eccles, 2012; Wang \& Holcombe, 2010). Accordingly, both disengaged profiles shared the most-negative perceptions of these dimensions, but novel findings pinpointed differences between the two disengaged profiles, with the Cynically disengaged students experiencing significantly less enthusiasm and encouragement from their teachers relative to the Moderately disengaged students. This result confirms the critical situation of the Cynically disengaged students, who do not find in their classroom environment supportive, which is important for promoting engagement (Shernoff et al., 2016) and buffering the risk for these students to remain marginal and eventually be 'thrown out' of school.

Regarding the engaged students, the study findings confirm previous person-oriented research indicating that they perceived higher resources in their learning environment (Salmela-Aro et al., 2016). Our multidimensional approach to school climate allowed us to detect that, in particular, the most-positive perception of Class management was a strong characterising feature of the adaptive Peacefully Engaged profile, while all the other profiles turned out to be more critical as regarding the teachers' ability to effectively manage everyday classroom activities without losing their patience. This finding confirms previous variable-oriented research that highlighted the association of better school structure with higher behavioural and emotional engagement (Wang \& Eccles, 2012) and lower burnout symptoms (Shih, 2015). Moreover, the Peacefully engaged students were more prone to perceive their teachers as enthusiastic and engaging, which are aspects that probably further sustain their adaptive profile. On their part, the Tenseley engaged students instead perceived more personal involvement and more support from their teachers. This result, along with these students' higher scores in agentic engagement and previous findings of links between agentic engagement and perceptions of teacher support (Matos et al., 2018), suggests that students handle their feelings of stress and cynicism by first asking for and then accepting the teacher's help.

Regarding the School Atmosphere, the Cynically disengaged students were the most negative on all dimensions, with the Sense of belonging approaching the lowest point, which confirms the severe malaise experienced by these students in school. Generally, students in both disengaged profiles perceived school atmosphere as less satisfying than students in the engaged profiles, as could be expected on the basis of variable-oriented studies on the associations between school climate and student engagement (Fatou \& Kubiszewski, 2018; Lombardi et al., 2019). Interestingly, negative feelings also were reported, especially by the Cynically disengaged students, with respect to peer relationships, showing that their discomfort is not restricted to learning aspects but invades the relational sphere. This result complements those of a qualitative study showing that positive social interactions are very relevant for students' and teachers' conceptualizations of engagement (Fredericks et al., 2016).

Overall, the Peacefully and Tensely engaged students showed a positive perception of the school atmosphere, but they also reported marked differences. For example, while students in both groups reported similar perceptions of their relations with teachers, the Tenseley engaged students perceived better relations with peers. This indicates that their higher levels of exhaustion and cynicism toward school were not accompanied by scattered discontent with their relational environment. However, these students also reported less-positive perceptions of the educational climate, thus revealing their difficulty in grasping the importance and beauty of learning in their school. This result is consistent with a 
previous person-oriented study indicating that students in an 'engaged-exhausted' profile, compared with purely engaged students, tended to perceive school as having lower value (Tuominen-Soini \& Salmela-Aro, 2014). Moreover, Tenseley engaged students reported a lower Sense of belonging and the feeling that teachers treat students unfairly. This result confirms findings in variable-oriented studies (i.e., that perceived classroom justice plays an important role on engagement and wellbeing) (Mameli et al., 2018; Molinari \& Mameli, 2018).

While more research at greater depth is needed into the above-reported associations (see also the Limitation and Future directions section), some of our findings pinpoint several aspects that can be translated into practical suggestions for empowering teachers in reflecting and intervening concerning the learning environment. For instance, the finding that the Cynically disengaged students, which comes out as the most critical profile, were the most negative on Positive teaching and Encouragement highlights their feeling of distance and isolation that, together with the low level of relationships with their peers, make up the picture of early adolescents perceiving generalized and serious school maladjustment. For the Tenseley engaged students, who put in a lot of effort into their learning but are burned out, dimensions pertaining the management of class activities with fairness and enthusiasm for learning were considered as critical. Teachers wanting to address this form of distress could start by addressing these aspects in their everyday practice.

\section{Limitations and conclusion}

This study is not without limitations and therefore further research is needed to strengthen its findings. First and foremost, our cross-sectional and person-oriented approach, while providing insights into the different groups of students, did not allow us to infer the direction of associations between school and student engagement and burnout. Longitudinal research is certainly needed in this field (Grazia \& Molinari, 2020a) and further variableoriented studies could complement our findings. Notwithstanding these limits, this study provided first person-oriented results on the relatively less-investigated correlates of school climate. Further studies could improve the resulting knowledge by also considering other variables at the classroom (e.g., teacher characteristics) and individual (e.g., the influence of family and personality) levels.

In conclusion, the adoption of a person-oriented approach, together with a multidimensional view of engagement and a comprehensive conceptualization of school climate, allowed the emergence of insights contributing to a new perspective in the study of the learning environment, as well as adding information to previous studies on student engagement and burnout. Implications for teachers and school managers offer precious advice for reflecting on students' different perceptions of their learning environment, preventing difficulties and helping students to enjoy a positive experience of involvement at school.

Funding Open access funding provided by Università degli Studi di Parma within the CRUI-CARE Agreement.

Open Access This article is licensed under a Creative Commons Attribution 4.0 International License, which permits use, sharing, adaptation, distribution and reproduction in any medium or format, as long as you give appropriate credit to the original author(s) and the source, provide a link to the Creative Commons licence, and indicate if changes were made. The images or other third party material in this article 
are included in the article's Creative Commons licence, unless indicated otherwise in a credit line to the material. If material is not included in the article's Creative Commons licence and your intended use is not permitted by statutory regulation or exceeds the permitted use, you will need to obtain permission directly from the copyright holder. To view a copy of this licence, visit http://creativecommons.org/licenses/by/4.0/.

\section{References}

Aldridge, J. M., \& McChesney, K. (2018). The relationships between school climate and adolescent mental health and wellbeing: A systematic literature review. International Journal of Educational Research, 88, 121-145. https://doi.org/10.1016/j.ijer.2018.01.012

Appleton, J. J., Christenson, S. L., \& Furlong, M. J. (2008). Student engagement with school: Critical conceptual and methodological issues of the construct. Psychology in the Schools, 45(5), 369-386. https:// doi.org/10.1002/pits.20303

Archambault, I., Janosz, M., Fallu, J.-S., \& Pagani, L. S. (2009). Student engagement and its relationship with early high school dropout. Journal of Adolescence, 32(3), 651-670. https://doi.org/10.1016/j. adolescence.2008.06.007

Asparouhov, T., \& Muthén, B. (2014). Auxiliary variables in mixture modeling: Three-step approaches using M Plus. Structural Equation Modeling: A Multidisciplinary Journal, 21(3), 329-341. https://doi. org/10.1080/10705511.2014.915181

Authors. (2020). The emotional faces of agency. Manuscript submitted for publication

Bear, G. G., Yang, C., Chen, D., He, X., Xie, J. S., \& Huang, X. (2018). Differences in school climate and student engagement in China and the United States. School Psychology Quarterly, 33(2), 323-335. https://doi.org/10.1037/spq0000247

Bear, G. G., Harris, A., de Macedo, S., Lisboa, C., \& Holst, B. (2019). Perceptions of engagement and school climate: Differences between once-retained and multiple-retained students in Brazil. International Journal of School \& Educational Psychology, 7(1), 18-27. https://doi.org/10.1080/21683603. 2017.1376725

Berkowitz, R., Moore, H., Astor, R. A., \& Benbenishty, R. (2017). A research synthesis of the associations between socioeconomic background, inequality, school climate, and academic achievement. Review of Educational Research, 87(2), 425-469. https://doi.org/10.3102/0034654316669821

Cohen, J., McCabe, E. M., Michelli, N. M., \& Pickeral, T. (2009). School climate: Research, policy, practice, and teacher education. Teachers College Record, 111(1), 180-213.

Fatou, N., \& Kubiszewski, V. (2018). Are perceived school climate dimensions predictive of students' engagement? Social Psychology of Education, 21, 427-446. https://doi.org/10.1007/ s11218-017-9422-X

Fiorilli, C., Galimberti, V., Stasio, S. D., Chiacchio, C. D., \& Albanese, O. (2014). School burnout inventory (SBI) con studenti italiani di scuola superiore di primo e secondo grado. Psicologia Clinica Dello Sviluppo, 3, 403-423. https://doi.org/10.1449/78365

Fredricks, J. A., Blumenfeld, P. C., \& Paris, A. H. (2004). School engagement: Potential of the concept, state of the evidence. Review of Educational Research, 74(1), 59-109. https://doi.org/10.3102/00346 543074001059

Fredricks, J. A., Wang, M.-T., Schall Linn, J., Hofkens, T. L., Sung, H., Parr, A., \& Allerton, J. (2016). Using qualitative methods to develop a survey measure of math and science engagement. Learning and Instruction, 43, 5-15. https://doi.org/10.1016/j.learninstruc.2016.01.009

Gray, C., Wilcox, G., \& Nordstokke, D. (2017). Teacher mental health, school climate, inclusive education and student learning: A review. Canadian Psychology/psychologie Canadienne, 58(3), 203-210. https://doi.org/10.1037/cap0000117

Grazia, V., Mameli, C., \& Molinari, L. (2020). Adolescents' profiles based on student agency and teacher autonomy support: Does interpersonal justice matter? European Journal of Psychology of Education. https://doi.org/10.1007/s10212-020-00504-2

Grazia, V., \& Molinari, L. (2020a). School climate multidimensionality and measurement: A systematic literature review. Research Papers in Education. https://doi.org/10.1080/02671522.2019.1697735

Grazia, V., \& Molinari, L. (2020b). School climate research: Italian adaptation and validation of a multidimensional school climate questionnaire. Journal of Psychoeducational Assessment. https://doi.org/10. $1177 / 0734282920967141$ 
Jamal, F., Fletcher, A., Harden, A., Wells, H., Thomas, J., \& Bonell, C. (2013). The school environment and student health: A systematic review and meta-ethnography of qualitative research. BMC Public Health, 13, 798. https://doi.org/10.1186/1471-2458-13-798

Jelas, Z. M., Azman, N., Zulnaidi, H., \& Ahmad, N. A. (2016). Learning support and academic achievement among Malaysian adolescents: The mediating role of student engagement. Learning Environments Research, 19(2), 221-240. https://doi.org/10.1007/s10984-015-9202-5

Johnson, S. L. (2009). Improving the school environment to reduce school violence: A review of the literature. The Journal of School Health, 79(10), 451-465. https://doi.org/10.1111/j.1746-1561.2009. 00435.x

Janosz, M., Archambault, I., Morizot, J., \& Pagani, L. S. (2008). School engagement trajectories and their differential predictive relations to dropout. Journal of Social Issues, 64, 21-40. https://doi.org/10. 1111/j.1540-4560.2008.00546.X

Janosz, M., Georges, P., \& Parent, S. (1998). L'environnement socioéducatif à l'école secondaire: Un modèle théorique pour guider l'évaluation du milieu. Revue Canadienne De Psychoeducation, 27(2), 285-306.

Kutsyuruba, B., Klinger, D. A., \& Hussain, A. (2015). Relationships among school climate, school safety, and student achievement and well-being: A review of the literature. Review of Education, 3, 103-135. https://doi.org/10.1002/rev3.3043

Lawson, M. A., \& Lawson, H. A. (2013). New conceptual frameworks for student engagement research, policy, and practice. Review of Educational Research, 83(3), 432-479. https://doi.org/10.3102/00346 54313480891

Lemos, M. S., Gonçalves, T., \& Cadima, J. (2020). Examining differential trajectories of engagement over the transition to secondary school: The role of perceived control. International Journal of Behavioral Development, 44(4), 313-324. https://doi.org/10.1177/0165025419881743

Lombardi, E., Traficante, D., Bettoni, R., Offredi, I., Giorgetti, M., \& Vernice, M. (2019). The impact of school climate on well-being experience and school engagement: A study with high-school students. Frontiers in Psychology, 10, 2482. https://doi.org/10.3389/fpsyg.2019.02482

Mameli, C., Biolcati, R., Passini, S., \& Mancini, G. (2018). School context and subjective distress: The influence of teacher justice and school-specific well-being on adolescents' psychological health. School Psychology International, 39(5), 526-542. https://doi.org/10.1177/0143034318794226

Mameli, C., Caricati, L., \& Molinari, L. (2020). That's not fair! The effects of teacher justice and academic achievement on self and other's resistant agency. British Journal of Educational Psychology, 90, 933947. https://doi.org/10.1111/bjep.12335

Mameli, C., \& Passini, S. (2017). Measuring four-dimensional engagement in school: A validation of the student engagement scale and of the agentic engagement scale. TPM-Testing Psychometrics, Methodology in Applied Psychology, 24, 527-541. https://doi.org/10.4473/TPM24.4.4

Matos, L., Reeve, J., Herrera, D., \& Claux, M. (2018). Students' agentic engagement predicts longitudinal increases in perceived autonomy-supportive teaching: The squeaky wheel gets the grease. The Journal of Experimental Education, 86(4), 579-596. https://doi.org/10.1080/00220973.2018.1448746

Maxwell, S., Reynolds, K. J., Lee, E., Subasic, E., \& Bromhead, D. (2017). The impact of school climate and school identification on academic achievement: Multilevel modeling with student and teacher data. Frontiers in Psychology, 8, 2069. https://doi.org/10.3389/fpsyg.2017.02069

Molinari, L., \& Mameli, C. (2018). Basic psychological needs and school engagement: A focus on justice and agency. Social Psychology of Education, 21, 157-172. https://doi.org/10.1007/s11218-017-9410-1

Nylund, K. L., Asparouhov, T., \& Muthén, B. O. (2007). Deciding on the number of classes in latent class analysis and growth mixture modeling: A Monte Carlo simulation study. Structural Equation Modeling: A Multidisciplinary Journal, 14(4), 535-569. https://doi.org/10.1080/10705510701575396

Ramelow, D., Currie, D., \& Felder-Puig, R. (2015). The assessment of school climate: Review and appraisal of published student-report measures. Journal of Psychoeducational Assessment, 33(8), 731-743. https://doi.org/10.1177/0734282915584852

Reeve, J., \& Shin, S. H. (2020). How teachers can support students' agentic engagement. Theory into Practice, 59(2), 150-161. https://doi.org/10.1080/00405841.2019.1702451

Reaves, S., McMahon, S. D., Duffy, S. N., \& Ruiz, L. (2018). The test of time: A meta-analytic review of the relation between school climate and problem behavior. Aggression and Violent Behavior, 39, 100-108. https://doi.org/10.1016/j.avb.2018.01.006

Reschly, A. L., Huebner, E. S., \& Appleton, J. J. (2008). Engagement as flourishing: The contribution of positive emotions and coping to adolescents' engagement in school and with learning. Psychology in the Schools, 45(5), 419-431. https://doi.org/10.1002/pits.20306 
Reyes, M. R., Brackett, M. A., Rivers, S. E., White, M., \& Salovey, P. (2012). Classroom emotional climate, student engagement, and academic achievement. Journal of Educational Psychology, 104, 700-712. https://doi.org/10.1037/a0027268

Reynolds, K. J., Lee, E., Turner, I., Bromhead, D., \& Subasic, E. (2017). How does school climate impact academic achievement? An examination of social identity processes. School Psychology International, 38(1), 78-97. https://doi.org/10.1177/0143034316682295

Rudasill, K. M., Snyder, K. E., Levincon, H., \& Adelson, J. L. (2018). Systems view of school climate: A theoretical framework for research. Educational Psychology Review, 30, 35-60. https://doi.org/10. 1007/s10648-017-9401-y

Salmela-Aro, K., Moeller, J., Schneider, B., Spicer, J., \& Lavonen, J. (2016). Integrating the light and dark sides of student engagement using person-oriented and situation-specific approaches. Learning and Instruction, 43, 61-70. https://doi.org/10.1016/j.learninstruc.2016.01.001

Salmela-Aro, K., \& Read, S. (2017). Study engagement and burnout profiles among Finnish higher education students. Burnout Research, 7, 21-28. https://doi.org/10.1016/j.burn.2017.11.001

Salmela-Aro, K., Savolainen, H., \& Holopainen, L. (2009). Depressive symptoms and school burnout during adolescence: Evidence from two cross-lagged longitudinal studies. Journal of Youth and Adolescence, 38(10), 1316-1327. https://doi.org/10.1007/s10964-008-9334-3

Salmela-Aro, K., \& Upadyaya, K. (2014). School burnout and engagement in the context of demandsresources model. British Journal of Educational Psychology, 84, 137-151. https://doi.org/10.1111/ bjep. 12018

Shernoff, D. J., Kelly, S., Tonks, S. M., Anderson, B., Cavanagh, R. F., Sinha, S., \& Abdi, B. (2016). Student engagement as a function of environmental complexity in high school classrooms. Learning and Instruction, 43, 52-60. https://doi.org/10.1016/j.learninstruc.2015.12.003

Shih, S.-S. (2015). The relationships among Taiwanese adolescents' perceived classroom environment, academic coping, and burnout. School Psychology Quarterly, 30(2), 307-320. https://doi.org/10.1037/ spq0000093

Skinner, E., Furrer, C., Marchand, G., \& Kindermann, T. (2008). Engagement and disaffection in the classroom: Part of a larger motivational dynamic? Journal of Educational Psychology, 100(4), 765-781. https://doi.org/10.1037/a0012840

Steffgen, G., Recchia, S., \& Viechtbauer, W. (2013). The link between school climate and violence in school: A meta-analytic review. Aggression and Violent Behavior, 18(2), 300-309. https://doi.org/10. 1016/j.avb.2012.12.001

Thapa, A., Cohen, J., Guffey, S., \& Higgins-D’Alessandro, A. (2013). A review of school climate research. Review of Educational Research, 83(3), 357-385. https://doi.org/10.3102/0034654313483907

Tuominen-Soini, H., \& Salmela-Aro, K. (2014). Schoolwork engagement and burnout among Finnish high school students and young adults: Profiles, progressions and educational outcomes. Developmental Psychology, 50, 649-662. https://doi.org/10.1037/a0033898

Voelkl, K. E. (2012). School identification. In S. L. Christenson, A. L. Reschly, \& C. Wylie (Eds.), Handbook of research on student engagement (pp. 193-218). Springer.

Voight, A., \& Nation, M. (2016). Practices for improving secondary school climate: A systematic review of the research literature. American Journal of Community Psychology, 58(1-2), 174-191.

Yang, C., Sharkey, J. D., Reed, L. A., \& Dowdy, E. (2020). Cyberbullying victimization and student engagement among adolescents: Does school climate matter? School Psychology, 35(2), 158-169. https://doi. org/10.1037/spq0000353

Wang, M.-T., \& Degol, J. L. (2016). School climate: A review of the construct, measurement, and impact on student outcomes. Educational Psychology Review, 28(2), 315-352. https://doi.org/10.1007/ s10648-015-9319-1

Wang, M.-T., \& Eccles, J. S. (2012). Adolescent behavioral, emotional, and cognitive engagement trajectories in school and their differential relations to educational success. Journal of Research on Adolescence, 22(1), 31-39. https://doi.org/10.1111/j.1532-7795.2011.00753.x

Wang, M.-T., \& Holcombe, R. (2010). Adolescents' perceptions of school environment, engagement, and academic achievement in middle school. American Educational Research Journal, 47(3), 633-662. https://doi.org/10.3102/0002831209361209

Publisher's Note Springer Nature remains neutral with regard to jurisdictional claims in published maps and institutional affiliations. 